\title{
Spectrophotometric quantification of dolutegravir based on redox reaction with $\mathrm{Fe}^{3+} / 1,10$-phenanthroline
}

\author{
Swathi Naraparaju ${ }^{1^{*}}$ (D), Durai Ananda Kumar Thirumoorthy ${ }^{2}$, Sunitha Gurrala ${ }^{3}$, Asra Jabeen ${ }^{3}$ and
} Pani Kumar D. Anumolu ${ }^{3}$

\begin{abstract}
Background: A simple and sensitive spectrophotometric method was developed for the quantitative measurement of dolutegravir in pure form and pharmaceutical formulation. The present method was based on redox reaction between dolutegravir and ferric chloride, which upon complexation with 1,10-phenanthroline formed an orangecolored complex that showed absorption maximum at $520.0 \mathrm{~nm}$.

Results: The developed method obeyed linearity in the concentration range of $40.00-140.00 \mu \mathrm{g} / \mathrm{mL}$. The method was also validated as per International Council for Harmonization guidelines and the results were within acceptance values. The validated method was employed for the determination of dolutegravir in pharmaceutical dosage form and the percentage assay value was found to be 102.5, which is in agreement with its label claimed.

Conclusion: The developed redox-based colorimetric method could be used in the routine quality control analysis of dolutegravir present in various pharmaceutical dosage forms.
\end{abstract}

Keywords: Spectrophotometry, Dolutegravir, $\mathrm{Fe}^{3+} / 1,10-$ Phenanthroline, Redox reaction

\section{Background}

Dolutegravir is chemically $4 R,(12 \mathrm{a} S)-N$-(2,4-difluorobenzyl)7-hydroxy-4-methyl-6,8-dioxo-3,4,6,8,12,12a-hexahydro- $2 \mathrm{H}$ pyrido[1',2'4,5] pyrazino[2,1- $b][1,3]$ oxazine-9-carboxamide and used as second generation HIV-1 integrase strand transfer inhibitor $[1,2]$. The structure of dolutegravir was shown in Fig. 1.

Literature review on dolutegravir revealed several analytical methods for its quantification either alone or in combination with other drugs. Ultraviolet-visible spectrophotometric technique for the analysis of dolutegravir sodium in tablet formulation in methanol [3], ultraviolet spectroscopic method using hydrotropic solubilizing agents [4], high performance liquid chromatographic method for its stereoisomers $[5,6]$, high performance liquid

\footnotetext{
* Correspondence: swa.pharma@gmail.com

${ }^{1}$ Department of Pharmaceutical Chemistry, Gokaraju Rangaraju College of

Pharmacy, Hyderabad, Telangana 500 090, India

Full list of author information is available at the end of the article
}

chromatographic and high performance thin-layer chromatographic methods for its salt analysis [7, 8], ultra-performance liquid chromatographic method [9], and bioanalytical methods using high performance liquid chromatography [10] and high performance liquid chromatography-mass spectroscopy [11] were reported in literature. The methods reported for dolutegravir in combination with other antiviral drugs involved reverse phase-high performance liquid chromatographic [12-19], ultra-performance liquid chromatographic [20], and normal phase high performance liquid chromatographic methods using rat plasma [21].

Iron [III] salts play an important role in spectrophotometric quantification of many pharmaceuticals. Ferric form $\left(\mathrm{Fe}^{3+}\right)$ of iron acts as oxidizing agent and causes oxidation of analyte under study and itself reduces to ferrous $\left(\mathrm{Fe}^{2+}\right)$ form. The later ions complex with reagent and produces chromophoric complex, which has $\lambda_{\max }$ in visible region. 1,10-Phenanthroline is a heterocyclic 
<smiles>CC1CCOC2Cn3cc(C(=O)NCc4ccc(F)cc4F)c(=O)c(O)c3C(=O)N12</smiles>

Fig. 1 Structure of dolutegravir

compound and known as a redox indicator, because of its ability to make complexes with various metal ions. Determination of Fe(II) and/or ruthenium (II)-1,10-phenanthroline complexes are well documented in the literature [22-25].

Although many instrumental techniques are available till date, still spectrophotometry plays a significant role in micro/nanogram level analysis of pharmaceuticals. It is simple, low time, and labor-consuming and easy to perform analysis using ultraviolet-visible spectrophotometer. Chromatographic methods, such as high-performance liquid chromatography, high-performance thin-layer chromatography, ultra-performance liquid chromatography, and high-performance liquid chromatography-mass spectroscopy require lavish instrument set-up, skilled operators, expensive solvents, and tedious extraction procedures, unlike colorimetric methods [26, 27]. As to date, no simple colorimetric method was developed for dolutegravir (using $\mathrm{Fe}^{3+} / 1,10$-phenanthroline) to the best of our knowledge. In view of the above facts, a simple, sensitive, and extraction- free colorimetric method was attempted for dolutegravir using $\mathrm{Fe}^{3+} / 1,10$-phenanthroline as chromogenic reagent. The same with success adopted for the ascertainment of dolutegravir in pharmaceutical formulation.

\section{Methods}

\section{Instrument}

The method was established by utilizing analytical grade chemicals and reagents. Dolutegravir standard gift sample was provided by Hetero Drugs Pvt. Ltd. and marketed solid dosage form (Tivicay) was procured from local pharmacy. The absorbance of the analytical solutions was determined by using double-beam Shimadzu Ultraviolet-Visible Spectrophotometer 1800. Spectral bandwidth $0.1 \mathrm{~nm}$, wavelength accuracy $\pm 0.1 \mathrm{~nm}$ and a pair of $1 \mathrm{~cm}$ path length matched quartz cells were included in it.

\section{Chemicals and reagents \\ 1,10-phenanthroline reagent $(0.5 \% \mathrm{w} / \mathrm{v})$}

The reagent, 1,10 -phenanthroline $(0.5 \mathrm{~g})$ was accurately weighed and dissolved in sufficient methanol (in a volumetric flask) to produce $100 \mathrm{~mL}$.

\section{Ferric chloride reagent $(0.3 \% \mathrm{w} / \mathrm{v})$}

Ferric chloride $(0.3 \mathrm{~g})$ was weighed accurately and dissolved in sufficient distilled water (in a volumetric flask) to produce $100 \mathrm{~mL}$.

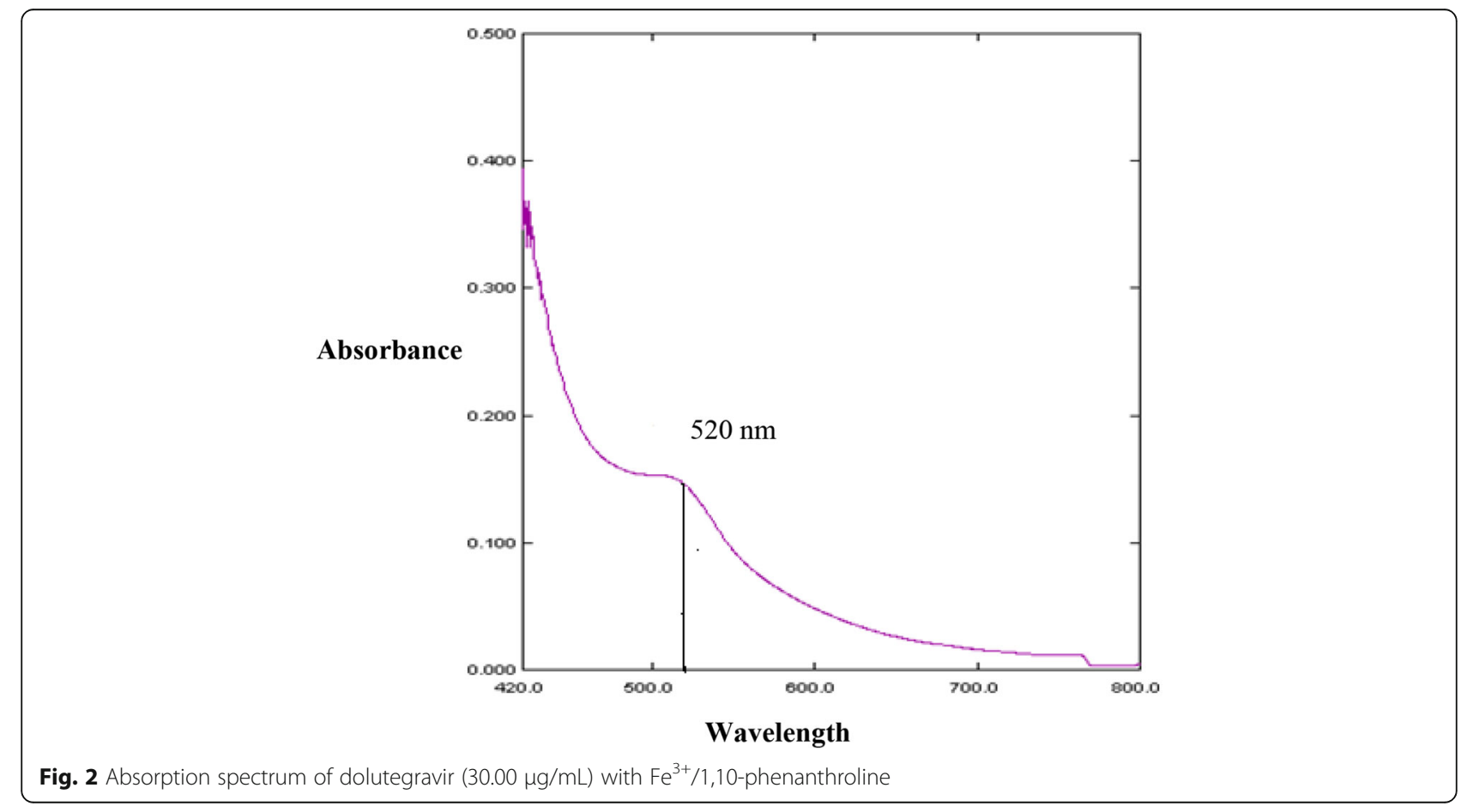




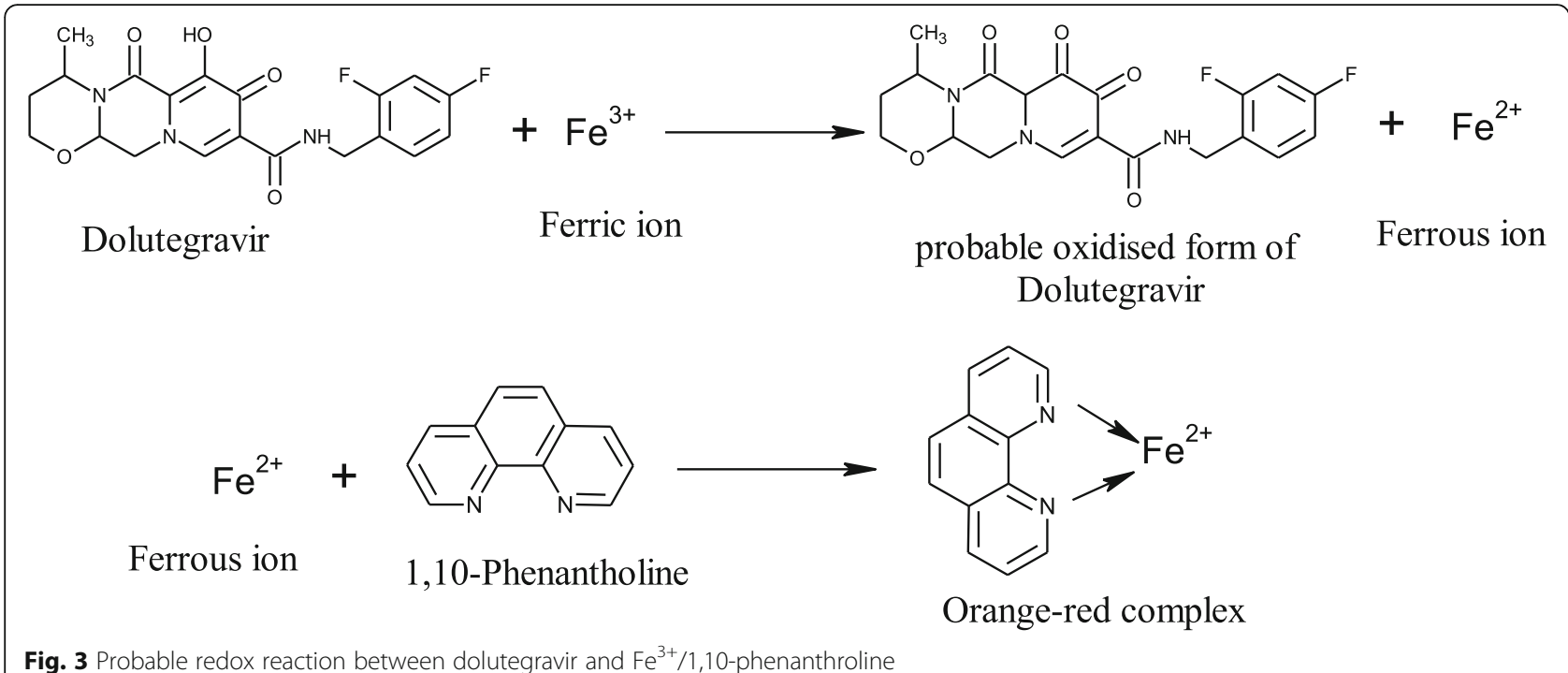

\section{Dolutegravir standard stock solution}

The stock solution of dolutegravir $(1000.00 \mu \mathrm{g} / \mathrm{mL})$ was made by solubilizing $10 \mathrm{mg}$ in $10 \mathrm{~mL}$ of acetonitrile and water (1:1). The solution was further diluted with distilled water to get the required concentration of dolutegravir for the $\lambda_{\max }$ determinations and for further analysis.

\section{Analysis of dolutegravir using $\mathrm{Fe}^{3+} / 1,10$-phenanthroline} Aliquots of $0.4,0.6,0.8,1.0,1.2$, and $1.4 \mathrm{~mL}$ of dolutegravir standard solution $(1000.00 \mu \mathrm{g} / \mathrm{mL})$ were progressively taken in to $10 \mathrm{~mL}$ volumetric flasks. To this ferric chloride solution $(2 \mathrm{~mL}, 0.3 \% \mathrm{w} / \mathrm{v}), 1,10$-phenanthroline solution $(1 \mathrm{~mL}, 0.5 \% \mathrm{w} / \mathrm{v})$ were added and shaken vigorously and lay aside for $15 \mathrm{~min}$ to ensure the color development through redox-coupling reaction. The volume of the volumetric flask was made up to the mark with double distilled water to accord the ultimate concentrations holding $40.00-140.00 \mu \mathrm{g} / \mathrm{mL}$ of dolutegravir.
Blank solutions were made by adopting identical methodology mentioned above, by omitting the corresponding analyte. Then the absorbance of the colored compound was recorded at $520.0 \mathrm{~nm}$ against corresponding blank. All measurements were recurrent six-fold for every concentration.

\section{Method optimization}

The analytical method was optimized for the reagent concentration (ferric chloride and 1,10-phenanthroline), time for color development and mole ratio of the reaction and the details were provided in next sections.

\section{Method validation}

The proof of the method was established based on linearity, accuracy, precision, sensitivity, and robustness according to International Council for Harmonization guidelines [28].

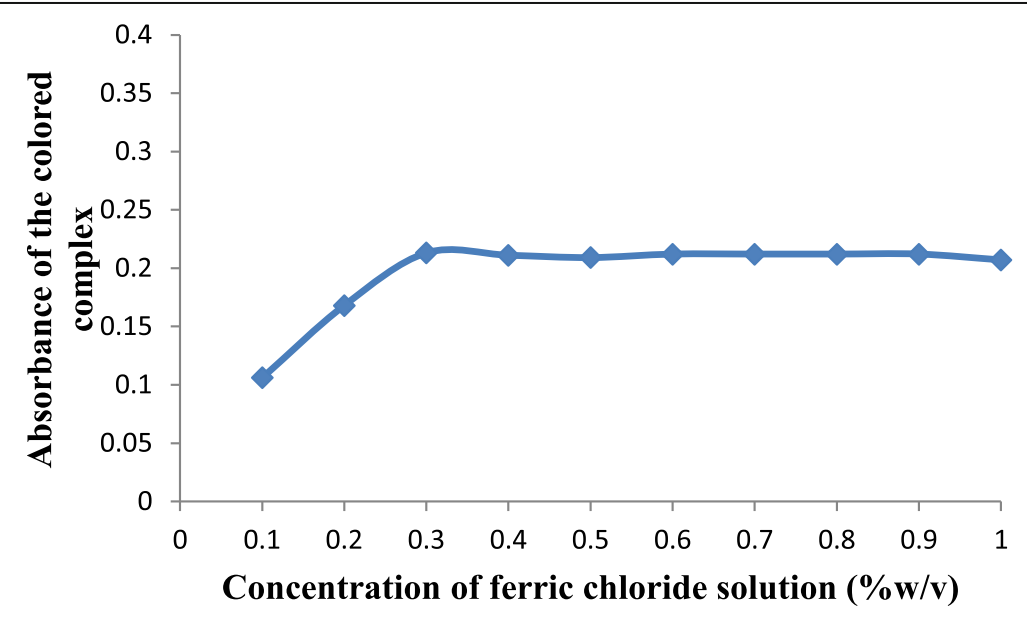

Fig. 4 Effect of concentration of ferric chloride on the absorbance of colored complex at $520.0 \mathrm{~nm}$ 


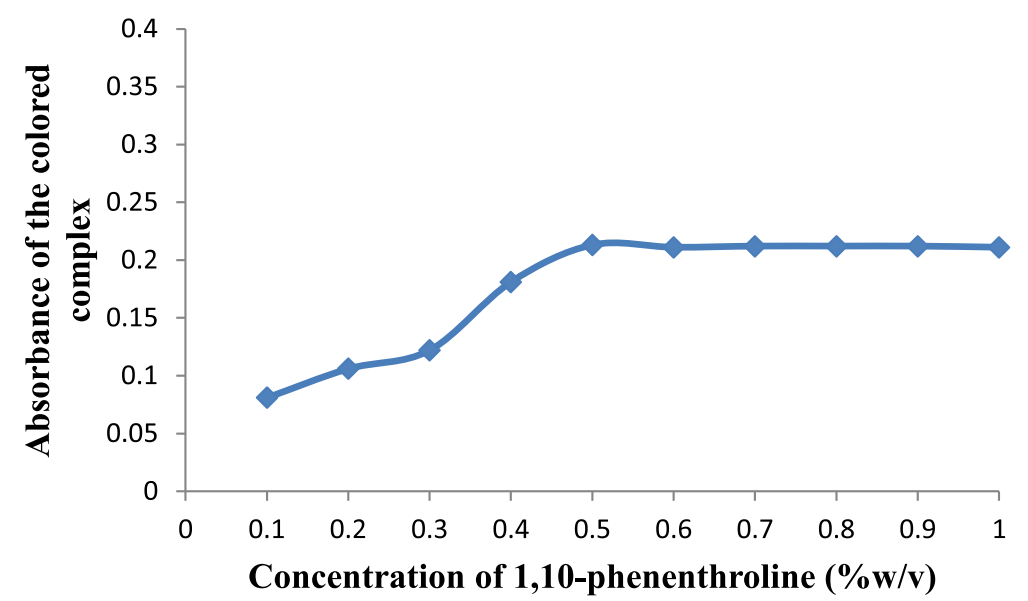

Fig. 5 Effect of concentration of 1,10-phenanthroline on the absorbance of colored complex at $520.0 \mathrm{~nm}$

\section{Linearity}

The linearity was examined in pure solutions $(n=6)$ over the concentration span of $40.00-140.00 \mu \mathrm{g} / \mathrm{mL}$ for dolutegravir. Calibration curve was plotted and from that slope, intercept, and correlation coefficient were computed.

\section{Accuracy}

The accuracy of the methodology was decided by recording the recoveries of the analyte using method of standard additions. Distinct levels of standard solutions $(80,100$, and $120 \%)$ of dolutegravir was spiked to prequantified samples and analyzed by proposed method. Each sample was prepared in triplicate at each level. The mean percentage recoveries and percentage relative standard deviation were figured out statistically.

\section{Precision}

Precision is the level of repeatability of results as reported between samples analyzed on identical day (intra-day) and samples scampered on three completely distinct days (inter day) in order to examine the intra- and inter-day variant in the method. Solutions accommodating 40.00, 80.00, and $140.00 \mu \mathrm{g} / \mathrm{mL}$ of dolutegravir were subjected to the present spectrophotometric method. The discrepancies in the absorbance of the analyte solutions on intra- and inter-day were deliberately expressed in percentage relative standard deviation.

\section{Sensitivity and robustness}

Sensitivity of the method was denoted by limit of detection and limit of quantification values, determined based on standard calibration curve. They were calculated using the formulae $3.3 \sigma / \mathrm{s}$ and $10 \sigma / \mathrm{s}$, respectively, where " $\sigma$ " is the standard deviation of the $y$ intercept of the regression equation and " $s$ " is the slope of the calibration curve. Sandell's sensitivity was calculated from the ratio of molecular weight and molar absorptivity of the dolutegravir. Further the

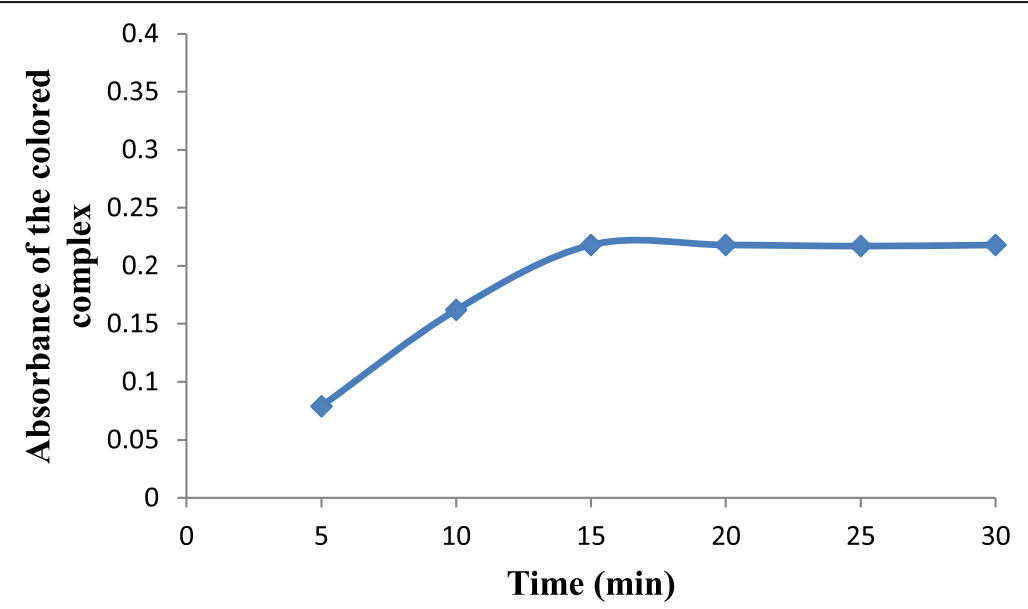

Fig. 6 Effect of time on the stability of colored complex at $520.0 \mathrm{~nm}$ 


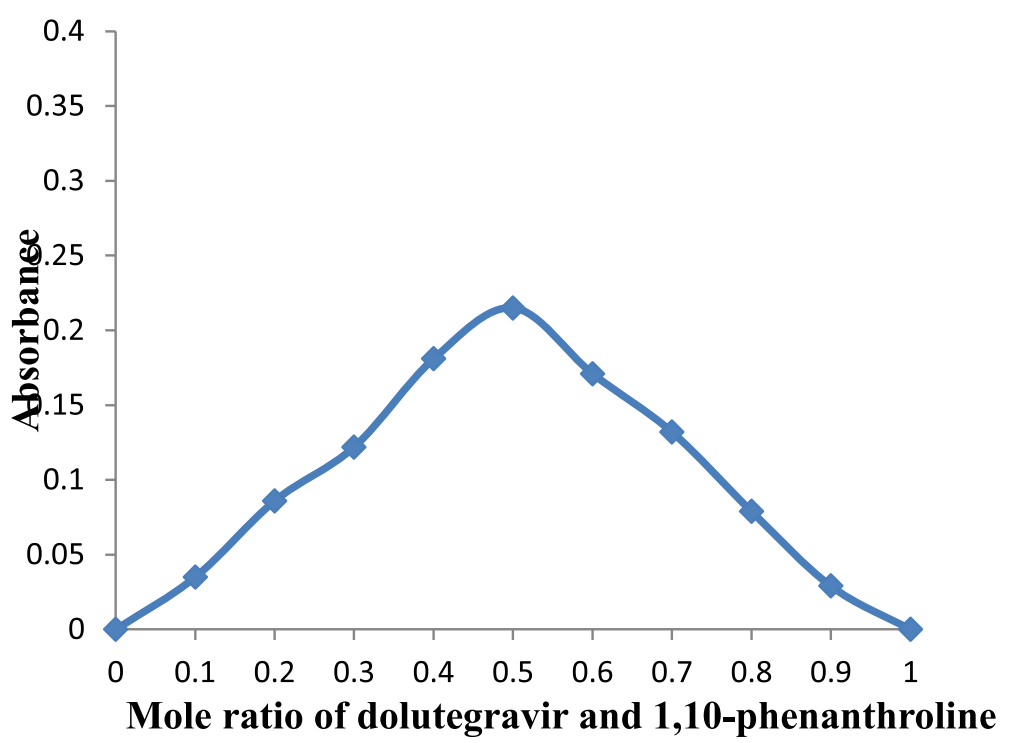

Fig. 7 Job's continuous variation plot for the analytical method

robustness of the analytical method was established by measuring the absorbance of the colored complex by making small changes in the concentration of ferric chloride and 1,10-phenanthroline.

\section{Assay of dolutegravir}

Twenty tablets of dolutegravir (Tivicay) were weighed accurately and ground to fine powder. A quantity of powder analogous to $200 \mathrm{mg}$ of dolutegravir was dissolved in acetonitrile and water (1:1), the contents were shaken thoroughly for $5 \mathrm{~min}$. Then, the volume was done up to $10 \mathrm{~mL}$ with acetonitrile and water and screened through Whatmann's filter paper (No. 42). To the $1 \mathrm{~mL}$ of above filtrate, $2 \mathrm{~mL}$ of ferric chloride solution $(0.3 \% \mathrm{w} / \mathrm{v}), 1 \mathrm{~mL}$ of 1,10 -phenanthroline reagent $(0.5 \% \mathrm{w} / \mathrm{v})$ were added and shaken vigorously. The emerged solution was diluted up to $10 \mathrm{~mL}$ with double distilled water and the colored chromogen was spectrophotometrically measured at $520.0 \mathrm{~nm}$ against the corresponding blank.

\section{Results}

The reaction of dolutegravir with ferric chloride in the presence of 1,10-phenanthroline resulted in the formation of orange colored product, which showed $\lambda_{\max }$ at $520.0 \mathrm{~nm}$ (Fig. 2). The probable reaction mechanism was shown in Fig. 3.

The method was optimized utilizing different concentrations of ferric chloride and 1,10-phenanthroline by varying one factor at a time. The effect of concentration of ferric chloride and 1,10-phenanthroline on the formation of colored complex was studied

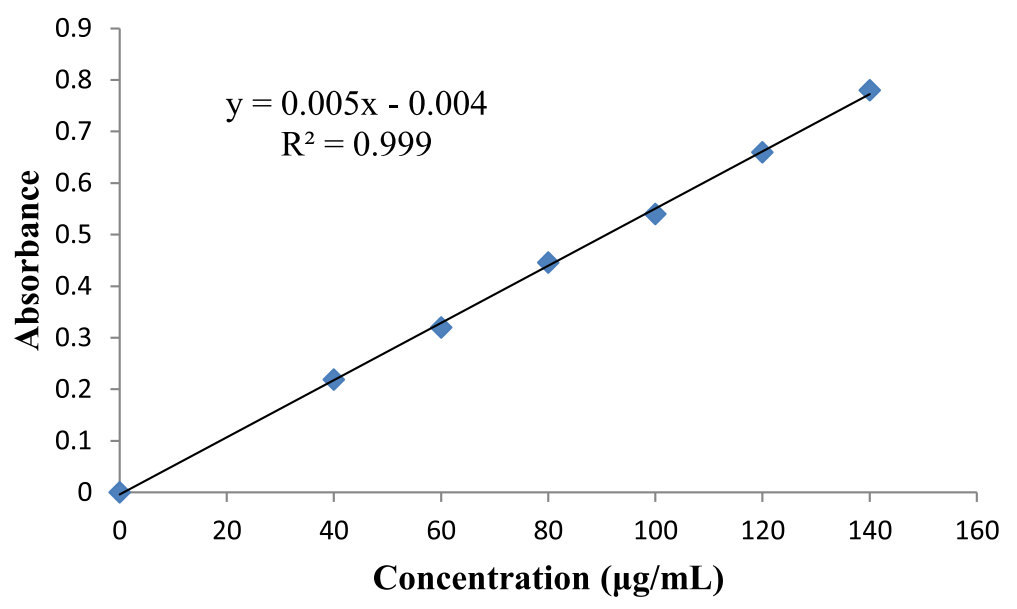

Fig. 8 Calibration plot of dolutegravir 
Table 1 Accuracy studies of dolutegravir for developed analytical method

\begin{tabular}{|c|c|c|c|c|c|c|c|c|}
\hline $\begin{array}{l}\text { Drug name } \\
\text { (brnad name) }\end{array}$ & $\begin{array}{l}\text { Recovery } \\
\text { level \% }\end{array}$ & $\begin{array}{l}\text { Amount Taken } \\
(\mu \mathrm{g} / \mathrm{mL}) \\
(\mathrm{A})\end{array}$ & $\begin{array}{l}\text { Amt of drug } \\
\text { spiked }(\mu \mathrm{g} / \mathrm{mL}) \\
\text { (B) }\end{array}$ & $\begin{array}{l}\text { Total amount } \\
\text { of drug } \\
(\mu \mathrm{g} / \mathrm{mL}) \\
(A+B)\end{array}$ & $\begin{array}{l}\text { Total amt } \\
\text { of drug } \\
\text { found }^{\mathrm{a}} \\
(\mu \mathrm{g} / \mathrm{mL})\end{array}$ & $\begin{array}{l}\text { Amt of drug } \\
\text { recovered } \\
(\mu \mathrm{g} / \mathrm{mL})\end{array}$ & $\begin{array}{l}\text { \%Amt } \\
\text { recovered }\end{array}$ & $\% \mathrm{RSD}^{c}$ \\
\hline \multirow[t]{3}{*}{ Dolutegravir (Tivicay) } & 80 & 50.00 & 40.00 & 90.00 & 89.73 & 39.73 & 99.3 & 0.69 \\
\hline & 100 & 50.00 & 50.00 & 100.00 & 100.80 & 50.80 & 101.6 & 0.74 \\
\hline & 120 & 50.00 & 60.00 & 110.00 & 112.00 & 62.00 & 103.3 & 0.72 \\
\hline
\end{tabular}

${ }^{a}$ Mean of three determinations

${ }^{\mathrm{b}}$ Mean of three determinations calculated with respect to amount of drug spiked (B)

${ }^{\mathrm{c}}$ Percentage relative standard deviation

separately by adding $2 \mathrm{~mL}$ of different concentrations of ferric chloride and $1 \mathrm{~mL}$ of 1,10-phenanthroline by varying one factor at a time. Both were taken at the concentration range of $0.1,0.2,0.3,0.4,0.5,0.6,0.7$, $0.8,0.9$, and $1.0 \% \mathrm{w} / \mathrm{v}$, while the concentration of dolutegravir was fixed at $40 \mu \mathrm{g} / \mathrm{mL}$. The details were shown in Figs. 4 and 5. Constant and maximum color development was observed with $0.3 \% \mathrm{w} / \mathrm{v}$ of ferric chloride and $0.5 \% \mathrm{w} / \mathrm{v}$ of 1,10-phenanthroline. Hence, the same were considered for the analysis.

The optimum reaction time was determined by monitoring the color development at different time intervals $(5,10,15,20,25$, and $30 \mathrm{~min})$. Maximum absorbance values were obtained at $15 \mathrm{~min}$ for dolutegravir (Fig. 6). Thereafter, the color developed was stable and the absorbance was constant up to $5 \mathrm{~h}$ under optimized conditions.

Stoichiometry of the reaction was studied by continuous variation method. Equimolar solutions of dolutegravir $\left(9.54 \times 10^{-5} \mathrm{M}\right)$ and 1,10-phenanthroline were prepared by keeping other reaction conditions same as the analytical method discussed earlier. The drug and reagent (1,10-phenanthroline) were mixed in various proportions to produce different mole ratio values $(0,0.1,0.2,0.3,0.4,0.5,0.6,0.7,0.8,0.9$, and 1.0). A mole ratio of 0.5 gave the highest absorbance value, which is indicated by the stoichiometric relationship shown in Fig. 7.

The method was further justified as per International Council for Harmonization guidelines to prove its usefulness for quality control analysis of dolutegravir. The developed methodology obeyed Beer's law within the concentration range of $40.00-140.00 \mu \mathrm{g} / \mathrm{mL}$. Linear regression analysis of the data given the equation $y=$ $0.0055 x-0.004$ with correlation coefficient 0.999 . The relationship between the drug concentration and absorbance is verified from linear regression studies $\left(r^{2}=0.999\right.$, Fig. 8).

The recovery of the analyte in standard addition method was utilized to establish the accuracy in the method. The percentage recoveries and percentage relative standard deviation were computed and reported (Table 1). The percentage recoveries were varied between 99.7 and 101.8\% for dolutegravir and the percentage relative standard deviation values were less than 2.0.

The repeatability and intermediate precision of the method were evaluated using three different levels of dolutegravir $(40.00,80.00$, and $140.00 \mu \mathrm{g} / \mathrm{mL})$. The results were summarized in Table 2 and the percentage relative standard deviation values were found to be satisfactory $(<2.0)$.

The responsiveness of the methodology was resolute with reference to limit of detection and limit of quantification. The method established 1.52 and $4.60 \mu \mathrm{g} / \mathrm{mL}$ as limit of detection and limit of quantification, respectively and Sandell's sensitivity was found to be $0.182 \mu \mathrm{g} / \mathrm{cm}^{2}$ for dolutegravir (Table 3).

The robustness of the proposed method was established by evaluating the influence of the small variations in the concentration of ferric chloride and 1,10-phenanthroine solutions both at $0.3 \pm 0.1$ and $0.5 \pm 0.1 \% \mathrm{w} / \mathrm{v}$, respectively. The results indicated that these changes did not greatly affect the absorbance of the formed colored complex.

The contemplated method was adopted to estimate the dolutegravir content in marketed formulation (Tivicay). The $\%$ assay value for dolutegravir was found to be 102.5

Table 2 Precision studies of dolutegravir for developed analytical method

\begin{tabular}{|c|c|c|c|c|}
\hline \multirow{2}{*}{$\begin{array}{l}\text { Conc } \\
(\mu \mathrm{g} / \\
\mathrm{mL})\end{array}$} & \multicolumn{2}{|l|}{ Intra-day } & \multicolumn{2}{|l|}{ Inter-day } \\
\hline & Amount found $^{\mathrm{a}}(\mathrm{AM} \pm \mathrm{SD})$ & $\% \mathrm{RSD}^{\mathbf{b}}$ & Amount found $^{\mathrm{a}}(\mathrm{AM} \pm \mathrm{SD})$ & $\% \mathrm{RSD}^{\mathbf{b}}$ \\
\hline 40.00 & $39.8 \pm 0.0004$ & 0.001 & $39.6 \pm 0.002$ & 0.005 \\
\hline 80.00 & $79.27 \pm 0.009$ & 0.011 & $79.24 \pm 0.008$ & 0.01 \\
\hline 140.00 & $140.7 \pm 0.10$ & 0.071 & $140.6 \pm 0.12$ & 0.09 \\
\hline
\end{tabular}

${ }^{a}$ Mean of three determinations

${ }^{\mathrm{b}}$ Percentage relative standard deviation 
Table 3 Optimized conditions in proposed method

\begin{tabular}{ll}
\hline Parameters & Dolutegravir \\
\hline Absorption wavelength $(\mathrm{nm})$ & 520.0 \\
Beer's law range $(\mu \mathrm{g} / \mathrm{mL})$ & $40.00-140.00$ \\
Limit of detection $(\mu \mathrm{g} / \mathrm{mL})$ & 1.52 \\
Limit of quantification $(\mu \mathrm{g} / \mathrm{mL})$ & 4.60 \\
Correlation coefficient $\left(r^{2}\right)$ & 0.999 \\
Slope $(\mathrm{m})$ & 0.005 \\
Intercept $(c)$ & -0.004 \\
Regression equation & $y=0.005 x-0.004$ \\
Molar Absorptivity $\left(\mathrm{L} \mathrm{mole}^{-1} \mathrm{~cm}^{-1}\right)$ & $0.023 \times 10^{5}$ \\
Sandell's sensitivity $\left(\mu \mathrm{g} / \mathrm{cm}^{2}\right)$ & 0.182 \\
\hline
\end{tabular}

(Table 4). The percentage relative standard deviation value was found to be $0.5(<2.0)$.

\section{Discussion}

The present colorimetric technique was rooted on redox reaction between dolutegravir and ferric chloride and further complexation with 1,10-phenanthroline [29]. The method was optimized by considering one factor at a time for the levels of ferric chloride and 1,10-phenanthroline and $0.3 \% \mathrm{w} / \mathrm{v}$ and $0.5 \% \mathrm{w} / \mathrm{v}$, respectively, were considered as optimum for the analysis. The analytical method was further corroborated for linearity, accuracy, precision, sensitivity, and robustness in line with International Council for Harmonization guidelines. A good linear response between dolutegravir concentration and its absorbance was noticed over a concentration range of 40.00$140.00 \mu \mathrm{g} / \mathrm{mL}$. The correlation-coefficient value reaching to unity indicated the same. The percentage relative standard deviation values less than 2.0 in recovery and precision studies indicated the accuracy and reproducibility of the method. The developed method was found to be sensitive based on its limit of detection $(1.52 \mu \mathrm{g} / \mathrm{mL})$ and limit of quantification $(4.60 \mu \mathrm{g} / \mathrm{mL})$ values. The validated methodology was employed for the quantification of dolutegravir in marketed formulation. The \%assay and percentage relative standard deviation values were within the acceptable limits. Thus, the quantification of dolutegravir in marketed formulation was proved to be fruitful by adopting the proposed analytical method.

Table 4 Data for assay studies of dolutegravir

\begin{tabular}{|c|c|c|c|c|c|}
\hline Drug name & $\begin{array}{l}\text { Brand } \\
\text { name }\end{array}$ & $\begin{array}{l}\text { Label } \\
\text { claim } \\
(\mathrm{mg})\end{array}$ & $\begin{array}{l}\text { Amount found } \\
(A M \pm S D)^{a}\end{array}$ & \%Assay & $\% \mathrm{RSD}^{\mathrm{b}}$ \\
\hline Dolutegravir & Tivicay & 200 & $205 \pm 0.004$ & 102.5 & 0.50 \\
\hline
\end{tabular}

${ }^{a}$ Mean value of three determinations

${ }^{\mathrm{b}}$ Percentage relative standard deviation

\section{Conclusion}

The proposed redox-based colorimetric method for the determination of dolutegravir using $\mathrm{Fe}^{3+} / 1,10$-phenanthroline as chromogenic reagent was found to be simple, rapid, and does not involve any extraction step. The method was validated for linearity, accuracy, precision, sensitivity, and robustness in line the International Council for Harmonization regulations. The validated method was adopted for the assay of dolutegravir in formulation and results were accorded with the label claim. The results additionally urged that there is no intervention of formulation excipients within the estimation. With these advantages, the proposed methodology can be adopted in routine quality control testing of dolutegravir in its pharmaceutical dosage forms.

\section{Acknowledgements \\ The authors are thankful to Prof. C.V.S. Subrahmanyam, Principal, Gokaraju Rangaraju College of Pharmacy and the Gokaraju Rangaraju Educational Society for providing necessary laboratory facilities.}

\section{Authors' contributions}

AJ had analyzed the samples and completed this work under the supervision of SN and PK. SG helped in experimental work. DAK helped in data analysis and manuscript editing. All authors together contributed for this research work. All authors have read and approved the manuscript.

\section{Authors' information}

SN: M. Pharm, Ph. D., Associate Professor \& Head, Department of

Pharmaceutical Chemistry, Gokaraju Rangaraju College of Pharmacy, Hyderabad-500 090, Telangana, India

DAK: M. Pharm, Ph. D., Assistant Professor, Department of Pharmaceutical Chemistry, JSS College of Pharmacy, JSS Academy of Higher Education and Research, SS Nagara, Mysuru, 570 015, Karnataka, India

SG: M. Pharm, Research Scholar, Department of Pharmaceutical Analysis,

Gokaraju Rangaraju College of Pharmacy, Hyderabad-500 090, Telangana, India AJ: M. Pharm, Research Scholar, Department of Pharmaceutical Analysis,

Gokaraju Rangaraju College of Pharmacy, Hyderabad-500 090, Telangana, India PK: M. Pharm, Ph. D., Associate Professor \& Head, Department of

Pharmaceutical Analysis, Gokaraju Rangaraju College of Pharmacy,

Hyderabad-500 090, Telangana, India

\section{Funding}

Not applicable

Availability of data and materials

All data generated or analyzed during this study are included in this article and the same can be provided to you whenever required.

Ethics approval and consent to participate

Not applicable

\section{Consent for publication}

Not applicable

\section{Competing interests}

No competing interests to declare.

\footnotetext{
Author details

'Department of Pharmaceutical Chemistry, Gokaraju Rangaraju College of Pharmacy, Hyderabad, Telangana 500 090, India. 'Department of Pharmaceutical Chemistry, JSS College of Pharmacy, JSS Academy of Higher Education and Research, SS Nagara, Mysuru, Karnataka 570 015, India. ${ }^{3}$ Department of Pharmaceutical Analysis, Gokaraju Rangaraju College of Pharmacy, Hyderabad, Telangana 500 090, India.
} 
Received: 22 June 2020 Accepted: 4 October 2020

Published online: 30 November 2020

\section{References}

1. Ribera E, Podzamczer D (2015) Mechanisms of action, pharmacology and interactions of dolutegravir. Enferm Infecc Microbiol Clin 33(1):2-8. https:// doi.org/10.1016/s0213-005x(15)30002-1

2. Min S, Song I, Borland J, Chen S, Lou Y, Fujjwara T, Piscitelli SC (2010) Pharmacokinetics and safety of S/GSK1349572, a next generation HIV integrase inhibitor, in healthy volunteers. Antimicrob Agents Chemother 54(1):254-258. https://doi.org/10.1128/AAC.00842-09

3. Girija BB, Kiran AB, Ravindra TS, Kakadsachein J, Sanjay Sudhakar P (2015) Development and validation of UV spectrophotometric method for estimation of dolutegravir sodium in tablet dosage form. Malaysian J Anal Sci 19(6):1156-1163

4. Mastannama SK, Ananta Sridhar T, Saidulu P (2015) A novel UVspectrophotometric method development and validation of dolutegravir in bulk and its laboratory synthetic mixture by using $8 \mathrm{M}$ urea as hydrotropic solubilising agent. Int J Pharm Sci Drug Res 7(4):370-375 http://ijpsdr.com/ index.php/ijpsdr/article/view/439

5. Chandrashekar Reddy K, Pavan Kumar KSR, Jagadeesh KV, Srinivas N, Sharma HK, Mukkanti K (2017) Stability-indicating HPLC method for the quantification (4S, 12R)-enantiomer and (4R, 12S)-diastereomer in dolutegravir sodium. Int J Pharm Pharm Res 9(2):52-63

6. Yashpalsinh NG, Rao S, Soni D (2018) Development and validation of chiral RP-HPLC method for quantification of optical isomers in dolutegravir sodium. Der Pharmacia Lettre 10(9):90-100

7. Girija BB, Sanjay SP, Kiran AB, Ravindra TS, Thorat RC (2016) Highperformance liquid chromatographic and high-performance thin layer chromatographic method for the quantitative estimation of dolutegravir sodium in bulk drug and pharmaceutical dosage form. Sci Pharm 84(2):305, 320. https://doi.org/10.3797/scipharm.1507-09

8. Shalini SP, Lavakesh Kumar O (2018) New analytical method development and validation for estimation of dolutegravir sodium in synthetic mixture using RP-HPLC. Asian J Pharm Edu Res 7(4):48-56

9. Wang X, Penchala SD, Amara A, Else L, McClure M, Boffito M (2016) A validated method for quantification of dolutegravir using ultra-performance liquid chromatography coupled with UV detection. Ther Drug Monit 38(3): 327-331. https://doi.org/10.1097/FTD.0000000000000286

10. Satyadev TNVSS, Bhargavi C, Syam Sundar B (2015) Development and validation of HPLC method for the determination of dolutegravir in human plasma. Der Pharmacia Sinica 6(4):65-72

11. Chantelle-Bennetto-Hood GT, Savina P, Edward P, Acosta (2014) A sensitive HPLC-MS/MS method for the determination of dolutegravir in human plasma. J Chromatography B Analyt Technol Biomed Life Sci 15:225-232. https://doi.org/10.1016/j.jchromb.2013.11.054

12. Devanna N, Benzil D, Ramachandraiah C (2017) Development and validation for the simultaneous estimation of dolutegravir and lamivudine in drug product by RP-HPLC. Int J Res Pharm Nano Sci 6(4):173-180

13. Kalpana T, Raja Rajeswari T, Ramana Reddy G (2017) Development and validation of analytical method for determination of dolutegravir sodium, lamivudine and tenofovir disoproxil fumerate using reverse phase high performance liquid chromatography. Der Phama Chem 9(8):117-127

14. Rajkumar P, Ganapathy S, Vamsi Krishna P, Surendra Babu L (2017) RP-HPLC method development and validation for the simultaneous determination of lamivudine, abacavir and dolutegravir in pharmaceutical dosage forms. World J Pharm Sci 5(5):168-181

15. Pal N, Srinivas Rao A, Ravi Kumar P (2016) Simultaneous HPLC method development and validation for estimation of lamivudine, abacavir and dolutegravir in combined dosage form with their stability studies. Asian J Chem 28(2):273-276. https://doi.org/10.14233/ajchem.2016.19116

16. Khaleel N, Abdul Rahaman SK (2015) A validated stability indicating RPHPLC method for simultaneous determination of abacavir, lamivudine and dolutegravir in bulk and pharmaceutical dosage form. World J Pharm Res 4(7):1453-1476

17. Mallikarjuna Rao N, Gowri Sankar D (2015) Development and validation of stability-indicating HPLC method for simultaneous determination of lamivudine, tenofovir and dolutegravir in bulk and their tablet dosage form. Future J Pharm Sci 1:73-77. https://doi.org/10.1016/j.jps.2015.11.002
18. Dhanwate SS, Pachauri AD, Ghode PD, Khandelwal KR (2019) Development and validation of analytical method for the estimation of lamivudine and dolutegravir sodium in dosage form. J Pharm Sci \& Res 11(8):2886-2890

19. Usha Rani K, Venkateswara Rao P, Srinivasa Rao N (2019) A new analytical method for determination of dolutegravir and rilpivirine in pharmaceutical formulation by RP-HPLC method. Int J Res Pharm Chem Anal 1(2):68-74. https://doi.org/10.33974/ijrpca.v1i3.119

20. Dubey S, Mahesh D (2018) Simultaneous estimation of lamivudune and dolutegravir by UPLC method. Int J Appl Pharm 10(1):46-52. https://doi.org/ 10.22159/ijap.2018v10i1.21156

21. Veeraswami B, Naveen VMK (2019) Development and validation of RPHPLC method for estimation of dolutegravir and rilpivirine in bulk and pharmaceutical dosage form and its applications to rat plasma. Asian J Pharm Clin Res 12(2):267-271. https://doi.org/10.22159/ajpcr. 2019.v12i2.29669

22. Banks CV, O'Laughlin JW (1957) Spectrophotometric determination of Ruthenium with 1,10-phenanthroline. Anal Chem 29(10):1412-1417. https:// doi.org/10.1021/ac60130a004

23. Wang Z, Cheng KL (1982) Spectrophotometric determination of iron with 1,10-phenanthroline in the presence of copper. Microchimica Acta 78:115124. https://doi.org/10.1007/BF01206697

24. Budhi O, Lee Wah L, Toyohide T (2008) Simultaneous determination of $\mathrm{Fe}(\mathrm{III})$ and $\mathrm{Fe}(\mathrm{II})$ ions via complexation with salicylic acid and 1,10phenanthroline in microcolumn ion chromatography. Anal Sci 24:14871492. https://doi.org/10.2116/analsci.24.1487

25. Veerabhadraswamy M, Devaraj TD, Jayanna BK (2018) Second derivative spectrophotometric determination of iron(II) and ruthenium(III) using 1,10phenanthroline. Anal Chem Lett 8(6):757-768. https://doi.org/10.1080/ 22297928.2018.1548944

26. Pani Kumar AD, Kavitha A, Vijaya Durga D, Himabindu S, Sunitha G, Ramakrishna K (2013) Spectrophotometric quantification of tadalafil by oxidative coupling reaction with MBTH reagent. Anal Chem Ind J 13(9):361-364

27. Sowjanya G, Mohana K (2019) Colorimetric approaches to drug analysis and applications - a review. Am J PharmTech Res 9(1):14-37

28. ICH, Q2 (R1) (2005) Validation of Analytical Procedures: Text and Methodology: International Conference on Harmonization.

29. Abu El-Enin MA, El-Wasseef DR, El-Sherbiny DT, El-Ashry SM (2009) Spectrophotometric determination of labetalol and lercanidipine in pure form and in pharmaceutical preparations using ferric-1,10-phenanthroline. Int J Biomed Sci 5(3):261-266

\section{Publisher's Note}

Springer Nature remains neutral with regard to jurisdictional claims in published maps and institutional affiliations.

\section{Submit your manuscript to a SpringerOpen ${ }^{\circ}$ journal and benefit from:}

- Convenient online submission

- Rigorous peer review

- Open access: articles freely available online

High visibility within the field

- Retaining the copyright to your article

Submit your next manuscript at $>$ springeropen.com 